\title{
Thermally Switchable Electrically Conductive Thermoset rGO/PK Self-Healing Composites
}

\author{
Esteban Araya-Hermosilla ${ }^{1}{ }^{(0)}$, Alice Giannetti ${ }^{2}$, Guilherme Macedo R. Lima ${ }^{3}{ }^{(}$, Felipe Orozco ${ }^{3}{ }^{(}$,

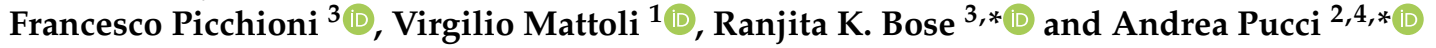 \\ 1 Center for Micro-BioRobotics, Istituto Italiano di Tecnologia, Viale Rinaldo Piaggio 34, Pontedera, \\ 56025 Pisa, Italy; esteban.araya@iit.it (E.A.-H.); virgilio.mattoli@iit.it (V.M.) \\ 2 Dipartimento di Chimica e Chimica Industriale, Università di Pisa, Via Moruzzi 13, 56124 Pisa, Italy; \\ alice.giannetti@hotmail.it \\ 3 Department of Chemical Product Engineering, Engineering and Technology Institute Groningen (ENTEG), \\ University of Groningen, Nijenborgh 4, 9747AG Groningen, The Netherlands; \\ g.de.macedo.rooweder.lima@rug.nl (G.M.R.L.); f.orozco.gutierrez@rug.nl (F.O.); f.picchioni@rug.nl (F.P.) \\ 4 Centro per l'Integrazione della Strumentazione dell'Università di Pisa (CISUP), Lungarno Pacinotti 43 , \\ 56126 Pisa, Italy \\ * $\quad$ Correspondence: r.k.bose@rug.nl (R.K.B.); andrea.pucci@unipi.it (A.P.); Tel.: +31-(0)503634486 (R.K.B.); \\ +39-0502219270 (A.P.)
}

check for updates

Citation: Araya-Hermosilla, E.; Giannetti, A.; Lima, G.M.R.; Orozco, F.; Picchioni, F.; Mattoli, V.; Bose, R.K.; Pucci, A. Thermally Switchable Electrically Conductive Thermoset rGO/PK Self-Healing Composites. Polymers 2021, 13, 339. https:// doi.org/10.3390/polym13030339

Academic Editor: Woo Cheong Received: 21 December 2020

Accepted: 18 January 2021

Published: 21 January 2021

Publisher's Note: MDPI stays neutral with regard to jurisdictional claims in published maps and institutional affiliations.

Copyright: (c) 2021 by the authors. Licensee MDPI, Basel, Switzerland. This article is an open access article distributed under the terms and conditions of the Creative Commons Attribution (CC BY) license (https:// creativecommons.org/licenses/by/ $4.0 /)$.

\begin{abstract}
Among smart materials, self-healing is one of the most studied properties. A self-healing polymer can repair the cracks that occurred in the structure of the material. Polyketones, which are high-performance thermoplastic polymers, are a suitable material for a self-healing mechanism: a furanic pendant moiety can be introduced into the backbone and used as a diene for a temperature reversible Diels-Alder reaction with bismaleimide. The Diels-Alder adduct is formed at around $50{ }^{\circ} \mathrm{C}$ and broken at about $120^{\circ} \mathrm{C}$, giving an intrinsic, stimuli-responsive self-healing material triggered by temperature variations. Also, reduced graphene oxide (rGO) is added to the polymer matrix (1.6-7 $\mathrm{wt} \%$ ), giving a reversible OFF-ON electrically conductive polymer network. Remarkably, the electrical conductivity is activated when reaching temperatures higher than $100{ }^{\circ} \mathrm{C}$, thus suggesting applications as electronic switches based on self-healing soft devices.
\end{abstract}

Keywords: self-healing; nanocomposite; reduced graphene oxide; smart polymer; polyketone; electrical conductivity

\section{Introduction}

Smart polymers are a category of materials able to change their features in response to the changing characteristics of the external environment [1]. A stimulus, such as a mechanical stress, a change in temperature or $\mathrm{pH}$, is sufficient to easily modify the structure of the material [2], thus suggesting useful applications in various fields. A change in the structure of the material triggered by external stimuli is for example used to produce carriers for drug delivery [3]. On this account, Convertine et al. developed a diblock copolymer with a temperature-responsive micellization [4], whereas Mahmoodzadeh et al. reported a $\mathrm{pH}$-sensitive triblock copolymer as a drug delivery system for cancer therapy [5]. Hajebi et al. proposed a temperature and $\mathrm{pH}$-responsive nanogel for the controlled release of doxorubicin [6]. Furthermore, smart polymers are used to fabricate high-performance sensors [7], in chromatography [8] and in the oil industry [9]. Nowadays, smart materials are also endowed with certain self-healing characteristics [10], that are fully inspired by the typical mechanisms of the biological world [11]. Notably, local and temporary mobility must be achieved to get an effective self-healing material but without hindering the structural application of the whole material. Only the damaged part should be involved in the self-healing process. For this reason, local healing is provided by heating or irradiating a small portion of the broken material, while the bulk structure can retain the overall 
toughness [12]. The stimulus can be also provided by electrical current, that is able to repair the material's damage thanks to the Joule effect [13]. The healing stimulus can be switched $\mathrm{ON}$ and OFF quickly depending on the kinetics of the healing mechanism and the chemical groups involved in the process [14]. From the above motivations, our group has extensively worked on self-healing thermosets based on the reversible Diels-Alder reaction [15-18]. From the perspective to produce scalable thermoset systems, our research has been focusing on the chemical modification of polyketone with primary amines via the Paal-Knorr reaction since it is a feasible route to produce these materials at an industrial level [19]. This synthetic approach provides several advantages; it can be carried out in bulk, without catalysts, with high yields at relatively mild conditions, and with water being the only byproduct [19]. In addition, it can be also carried out without any solvent or in various organic solvents depending on the physical and chemical properties of the amine compound [20]. A variety of primary amines can be used, making this synthesis a fast, cheap, and appealing approach to create polymers with almost any desired pendant functional group [21,22]. Self-healing thermosets have been efficiently prepared by modifying polyketone with furan groups which can undergo thermally reversible Diels-Alder reactions with maleimides compounds $[16,17,23,24]$. Diels-Alder adducts can be easily formed at $50{ }^{\circ} \mathrm{C}$ and broken via retro Diels-Alder reaction at around $120^{\circ} \mathrm{C}$, thus appearing very useful to repair surface scratches or bulk cracks of polymeric materials $[16,17,25]$. The mechanical properties of these materials can also be tuned by adding fillers within the matrix as demonstrated in earlier works $[13,15]$. Polyketones functionalized with furan groups and crosslinked with bismaleimide experienced the enhancement of their elastic and loss moduli and softening points thanks to the reinforcement provided by multi-walled carbon nanotubes (MWCNTs). In addition, the percolative networks created by the MWCNTs dispersions within the thermosets allowed for electrically-triggered self-healing phenomena [15].

In recent literature, graphene is reported to outperform carbon nanotubes in polymeric nanocomposites in terms of enhanced mechanical [26,27], thermal, and electrical properties [28]. Graphene is one of the most popular nanofiller due to its carbon-like nature, nanometric dimensions and high conjugation of the $\pi$ electrons. These characteristics render graphene as the most appealing filler in nanocomposites since it exerts its beneficial functions even at very low loading $(<2-5 \mathrm{wt} \%)[29,30]$. However, its poor dispersibility in solvents and irreversible aggregation in several media may limit its use [31]. An alternative to graphene is reduced graphene oxide (rGO) which is produced by the chemical or thermal reduction of graphene oxide. The residual functional groups remaining in the rGO structure make its dispersion easier and stable in water and polar organic solvents [32-35]. Furthermore, they increase the number of effective interactions with polymer matrices improving its homogeneous distribution in the solid host [36,37], leading to the preparation of polymeric nanocomposites [38-40], where rGO provides substantial electrical and mechanical properties [41-45]. Gudkov et al. demonstrate that with only $0.6 \mathrm{wt} \%$ of $\mathrm{rGO}$ dispersed in a polymeric matrix an electrical conductivity of $0.5 \mathrm{~S} / \mathrm{m}$ is achieved for the nanocomposite [46]. Cheng et al. added rGO as nanofiller into a PVA polymer matrix providing an improvement of the Young's modulus of about $80 \%$. Despite a good increase in the Young's modulus, a consequent drop of the elongation at break should be however taken into account $[47,48]$.

In the present work, we report the synthesis of a self-healing and electrically conductive nanocomposite that displays re-workability and tunable electrical and thermomechanical properties as a function of the rGO content added to the matrix. As starting material, we used polyketone obtained from the copolymerization of 30\% ethylene, 70\% propylene and $\mathrm{CO}(\mathrm{PK})$ and functionalized with furan moieties (PKFU) that act as diene in the reversible Diels-Alder crosslinking process and compatibilizer for the rGO filler $[13,15,16]$. Moreover, a new type of bismaleimide (BISM) was used as dienophile [13-17] due to its increased miscibility in polyketone that might allow for a faster reaction with PKFU in the bulk (Figure 1). Spectroscopic evidence confirmed the modification of polyketone via the Paal-Knorr reaction and the crosslinking of the final composites. The mechanical properties, 
recyclability, and reworkability of the final materials were evaluated by thermomechanical analyses. The final morphology of the materials and the dispersion of rGO in the polymeric matrix were characterized by SEM and the modulable OFF-ON electrical conductivity eventually determined as a function of the temperature.
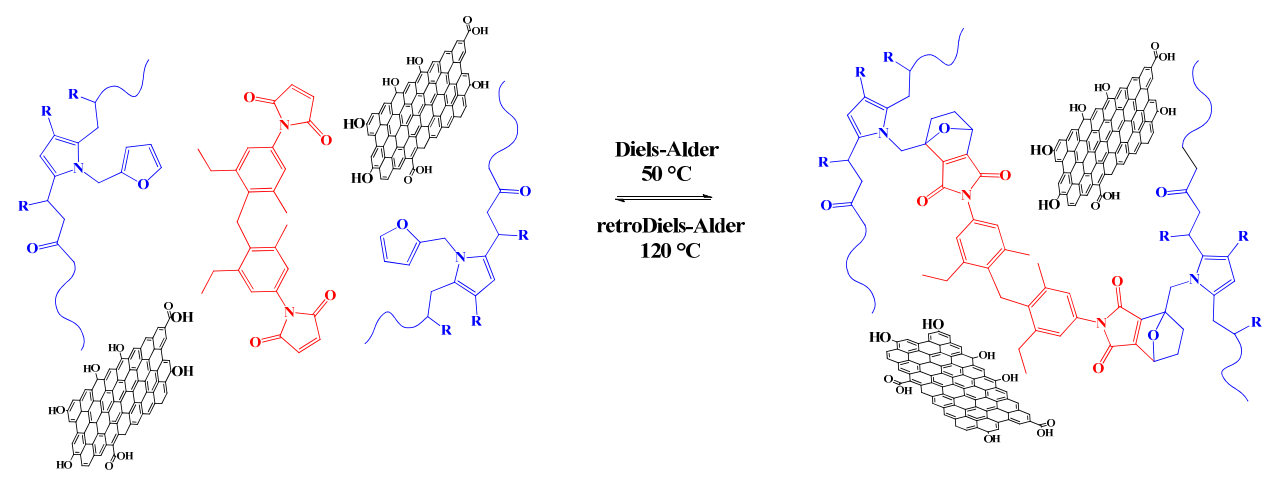

Figure 1. Schematic representation of the formation of the self-healing electrically-conductive nanocomposite based on the functionalized PK (blue), BISM (red) and the rGO (black) nanofiller.

\section{Materials and Methods}

Furfurylamine (FU $\geq 99 \%$ ) was purchased from Sigma-Aldrich (Milan, Italy). The amine was freshly distilled before use to remove the oxidized impurities, if any. Bis(3-ethyl5-methyl-4-maleimidophenyl)methane (BISM abcr 98\%, Karlsruhe, Germany), was used as the cross-linking agent. Reduced graphene oxide $(\mathrm{rGO})$ was purchased from Sigma-Aldrich (Milan, Italy), and used without any purification. It is composed by $>75 \% \mathrm{C}$ and $<5 \% \mathrm{~N}$, has a surface area of $103\left(\mathrm{~m}^{2} / \mathrm{g}\right)$ and an electric conductivity of $7111 \mathrm{~S} / \mathrm{m}$ (compressed powder). N-Methyl-2-pyrrolidone (NMP), deuterated chloroform $\left(\mathrm{CDCl}_{3}\right)$ used for ${ }^{1} \mathrm{H}$-NMR studies, were all purchased from Sigma-Aldrich and used as delivered. Chloroform $\left(\mathrm{CHCl}_{3}, 99.5 \%\right)$ was purchased from Sigma-Aldrich (Milan, Italy) and used as received. The alternating aliphatic polyketone was synthesized according to the reported procedure [49], using 30\% of ethylene and $70 \%$ of propylene to obtain the so-called polyketone 30 (PK).

\subsection{Furfurylamine Functionalization of Alternating Polyketone}

The chemical modifications of polyketone (PK) to yield PK with furan groups (PKFU) was carried out in bulk, following the reported procedure [17]. Briefly, $32.50 \mathrm{~g}$ of PK was preheated to the liquid state at $110^{\circ} \mathrm{C}$ and $14.39 \mathrm{~g}$ of FU were added dropwise during $20 \mathrm{~min}$. The reaction proceeded for $4 \mathrm{~h}$ and the color of the mixture changed from the typical yellow of the PK to the typical amber-brown of the functionalized polymer due to the presence of the pyrrole units. The resulting polymer was dissolved in $100 \mathrm{~mL}$ of chloroform and washed with Milli- $Q$ water to remove the unreacted amine, if any. The washed polymer was dried under air first, and then in a vacuum oven at $50^{\circ} \mathrm{C}$ for $48 \mathrm{~h}$, to remove any trace of solvent. The resulting polymer was frozen with liquid nitrogen and crushed to obtain a fine powder. The elemental composition of the samples was analyzed using the Euro EA elemental analyzer. The carbonyl conversion $\left(C_{c o}\right)$, i.e., the molar fraction of 1,4-dicarbonyl units reacted via the Paal-Knorr reaction, was calculated on the basis of elemental analysis using the following expression:

$$
C_{c o}=\frac{y}{y+x} \times 100 \%
$$

where $x$ and $y$ are the di-ketone and pyrrolic moles after conversion, respectively. $y$ was determined as follows:

$$
y=\frac{w t(N)}{A_{m}(N)}
$$


where $w t(N)$ are the grams of $N$ of the product as determined by elemental analysis and $A_{\mathrm{m}}(N)$ is the atomic mass of $N . x$ was then determined as follows:

$$
x=\frac{g_{\text {prod }}-y \times M_{w}^{y}}{M_{w}^{p k}}
$$

where $g_{\text {prod }}$ is the gram of the product, $M_{w}^{y}$ the molecular weight of the pyrrolic unit and $M_{w}^{p k}$ the molecular weight of the 1,4 di-ketone unit. From the ratio between $C_{c o}$ and the corresponding amount in the feed $\left(C_{c o}^{\text {feed }}\right)$, the conversion efficiency $\eta$ con be calculated with the following equation:

$$
\eta=\frac{C_{c o}}{C_{c o}^{f e e d}} \times 100 \%
$$

where $C_{c o}^{f e e d}$ corresponds to:

$$
C_{c o}^{f e e d}=\frac{M o l_{\text {amine }}}{M o l_{d-C O}} \times 100 \%
$$

where $\mathrm{Mol}_{\text {amine }}$ are the moles of amine and $\mathrm{Mol}_{d-\mathrm{CO}}$ the moles of dicarbonyl units in the feed.

\subsection{One Pot Reaction for the Preparation of the Cross-Linked Nanocomposite}

The thermoset nanocomposite was prepared by one-pot solvent-mix containing equimolar amounts of PKFU and BISM (at a furan/maleimide ratio of 1:1) and 1.6, 2.7, 4.3, 5.5 and $7.0 \mathrm{wt} \%$ of rGO. The reactants were previously dissolved in NMP $(0.87 \mathrm{~g}$ of BISM dissolved in $3 \mathrm{~mL}$ and $1.00 \mathrm{~g}$ of PKFU in $4 \mathrm{~mL}$ ) and the rGO (respectively 0.03, 0.05, 0.08, $0.103,0.13 \mathrm{~g}$ in $3 \mathrm{~mL}$ ) tip sonicated ( $400 \mathrm{~W}$ and $24 \mathrm{kHz}$ with UP $400 \mathrm{~S}$ probe in titanium with a $3 \mathrm{~mm}$ diameter tip and $100 \mathrm{~mm}$ length (Hielscher's H3, Hielscher, Teltow, Germany) for $5 \mathrm{~min}$ in NMP to disperse the nanofiller. The reaction mixture was heated up to $80^{\circ} \mathrm{C}$ for $24 \mathrm{~h}$ under stirring to form the cross-linked network. After cooling to room temperature, the solvent was removed under vacuum at $80{ }^{\circ} \mathrm{C}$ for $48 \mathrm{~h}$. The obtained nanocomposite was crushed after freeze drying with liquid nitrogen. The thermoset composed only with PKFU and BISM was synthesized as mentioned above and used as control sample.

\subsection{Preparation of Bars by Compression Moulding}

Sample bars (approximately $50 \mathrm{mg}$ of sample for a bar of $45 \mathrm{~mm}$ long, $5 \mathrm{~mm}$ wide and $1 \mathrm{~mm}$ thick) were obtained by compression moulding. The samples were moulded at $150{ }^{\circ} \mathrm{C}$ at 40 bars for $30 \mathrm{~min}$ and then cured at $50^{\circ} \mathrm{C}$ in an oven at atmospheric pressure for $24 \mathrm{~h}$. For the preparation of the bars, a FONTIJNE Vlaardingen press (Fontijne presses, Delft, The Netherlands) quipped with a temperature controller was used.

\subsection{Characterization}

ATR-FT-IR spectra were recorded using a Spectrum One instrument (Perkin-Elmer, Waltham, MA, U.S.), within the $4000-650 \mathrm{~cm}^{-1}$ and averaged over 32 scans.

${ }^{1} \mathrm{H}-\mathrm{NMR}$ spectra were recorded using a Varian Mercury Plus $400 \mathrm{MHz}$ machine (Bruker, Billerica, $\mathrm{MA}, \mathrm{USA}$ ), using $\mathrm{CHCl}_{3}$-d as a solvent.

The elemental composition of the polymer was determined by using an Elementar Vario Micro Cube (Milano, Italy) for nitrogen, carbon and hydrogen.

Microscopic morphology of the composite samples was observed by scanning electron microscopy (SEM) using a Dual Beam FIB/SEM Helios Nano-Lab 600i (FEI, Hillsboro, OR, USA) in a way similar to procedures previously reported [20].

Differential scanning calorimetry (DSC) was carried out using a TA DSC250 system (TA Instruments, New Castle, DE, USA) under $\mathrm{N}_{2}$ as described in previous studies $[13,15]$. 
Dynamic mechanical thermal analysis (DMTA) measurements were performed using a DMA-8000 machine (Perkin Elmer, Waltham, MA, USA) as reported in previous studies $[13,15]$.

The temperature dependent resistivity measurements were performed on square $6 \mathrm{~mm} \times 6 \mathrm{~mm}$ samples with $1.05 \mathrm{~mm}$ of thickness, connected with two copper electrodes to the opposite edge of the square: the temperature control was obtained by placing the sample on a thin ceramic plate substrate $(0.3 \mathrm{~mm}$ ) equipped with a gold resistance (on the bottom side, not in direct contact with sample) connected to a controllable power supply module. The temperature was monitored with a k-thermocouple brought in contact with the sample; the resistance was continuously measured using a High precision multimeter (Model 187, Fluke, Fluke Corporation, Everett, WA, USA) connected with the copper electrodes. Measurements were performed modulating the temperature by changing the current applied to the ceramic heater and waiting for the temperature stabilization [20].

Thermal degradation of the rGO and the derived nanocomposites was analyzed via thermogravimetric analysis (TGA) with a Mettler Toledo TGA/SDTA851 instrument (Mettler Toledo, Columbus, OH, USA) under nitrogen flux ( $80 \mathrm{~mL} / \mathrm{min})$. All samples were tested in agreement with procedures previously reported [48].

Raman spectroscopy has been performed using a Horiba Jobin Yvon Xplora ONE confocal Raman microscope (Horiba Scientific, Horiba Italy, Rome, Italy). The wavelength of the excitation laser was $542 \mathrm{~nm}$ and the power of the laser was kept below $1 \mathrm{~mW}$ to avoid sample heating [20].

\section{Results and Discussion}

\subsection{Furfurylamine Functionalization of Alternating Polyketone}

We prepared PKFU by a chemical modification of PK with furfurylamine via the Paal-Knorr reaction (Figure 2a).

(a)<smiles>[R]C(C)CC(=O)C([R])CC(C)=O</smiles>

PK

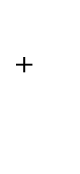

FU

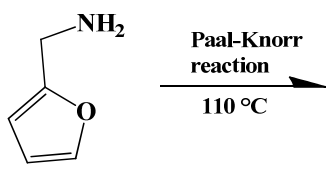<smiles>[R]c1cc(C(C)(C)C)n(Cc2ccco2)c1CC([R])(C)C(=O)CC([R])C(=O)CC([R])C</smiles>

PKFU

(b)<smiles>CCc1cc(N2C(=O)C=CC2=O)cc(C)c1Cc1c(C)cc(N2C(=O)C=CC2=O)cc1CC</smiles>

Figure 2. (a) Schematic representation of the polyketone modification with furfurylamine and (b) the chemical structure of the BISM.

The reaction was carried out in a 0.8 molar ratio between the 1,4-dicarbonyl groups of the PK and the amino groups according to the calculated carbonyl conversion. The functionalization of PK yielded a di-carbonyl conversion (CO \%) of $68.3 \%$ as determined from elemental analysis.

We confirmed the successful functionalization of PK by ${ }^{1} \mathrm{H}-\mathrm{NMR}$ (Figure 3), where the signal at 5.8 and $2.0 \mathrm{ppm}$ were respectively attributed to the hydrogen and to the methyl group of the pyrrole ring formed during the Paal-Knorr process. The peak at $4.9 \mathrm{ppm}$, attributed to the $\mathrm{CH}_{2}$ units connecting the pyrrole ring to the furan one, evidenced the 
presence of furan as a pendant group. The peaks at 7.3, 6.2 and $5.9 \mathrm{ppm}$ belong to the protons of the furan moieties, as reported earlier $[15,18]$. Notably, all peaks are attributed to PKFU, thus confirming that no residual amine was present after purification $[14,17]$.

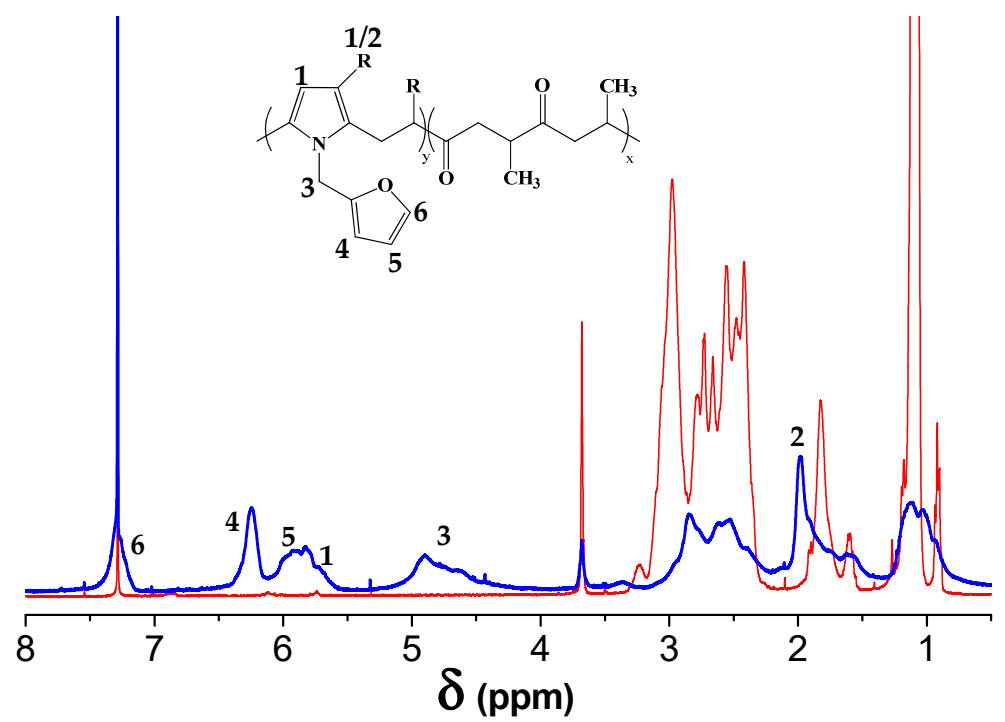

Figure 3. ${ }^{1} \mathrm{H}-\mathrm{NMR}$ spectrum of the pristine polymer $(\mathrm{PK})$ and of the polyketone modified with furfurylamine (PKFU).

Figure 4 shows the ATR-FTIR spectra of PK and PKFU. After the Paal-Knorr reaction occurred, the $\mathrm{C}=\mathrm{O}$ band centered at $1707 \mathrm{~cm}^{-1}$ decreased due to the disappearance of the 1,4-dicarbonyl moieties. The typical peak of the heterocyclic moieties appeared at $1507 \mathrm{~cm}^{-1}$ due to the $\mathrm{C}=\mathrm{C}$ stretching, confirming the presence of both furan and pyrrole groups. The peaks associated to the pyrrole units were found at $3115 \mathrm{~cm}^{-1}(\mathrm{C}=\mathrm{C}-\mathrm{H})$ and at $1345 \mathrm{~cm}^{-1}$ (C-N). In addition, we assigned the peaks at $3150 \mathrm{~cm}^{-1}(\mathrm{C}=\mathrm{C}-\mathrm{H})$, at $1073 \mathrm{~cm}^{-1}$ (C-O-C), and at $737 \mathrm{~cm}^{-1}$ (C-H bonds out-of-plane bending) to the furan pendant group. Finally, the stretching bands of aliphatic C-H of PK backbone and functional groups appeared between 2969 and $2873 \mathrm{~cm}^{-1}$ [13].

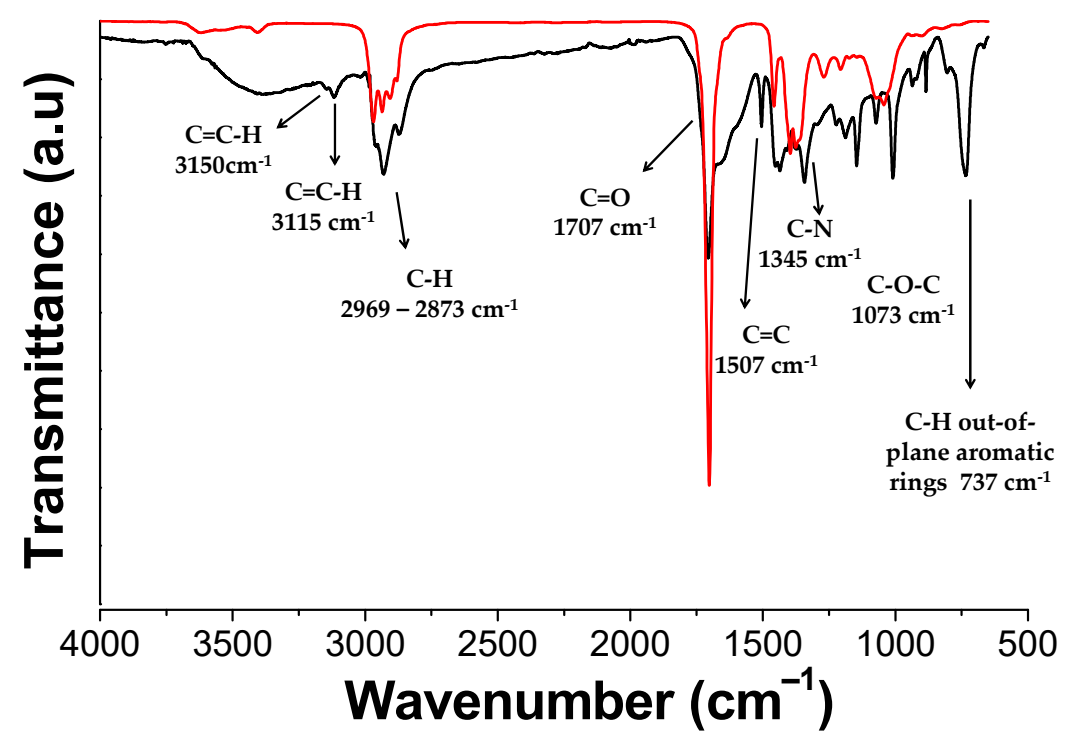

Figure 4. FT-IR spectrum of the pristine polymer (PK, red line) and of the polyketone modified with furfurylamine (PKFU, black line). 


\subsection{Preparation and Characterization of PKFU/BISM rGO Nanocomposites}

The bismaleimide (BISM, Figure $2 b$ ) was chosen as a cross-linker for various reasons. Notably, the Diels-Alder adduct is reversible, a fundamental feature for imparting thermoplasticity and self-healing characteristics to the material. Moreover, the creation of the network increases the softening point of the PK, which has been calculated to be around $21{ }^{\circ} \mathrm{C}$. The achieved softening temperature depends on the ratio between BISM and the furan pendant groups [16]. Figure 5 shows the ATR-FTIR spectrum of the polymer network before and after crosslinking. The peaks at 1182 and $1378 \mathrm{~cm}^{-1}$ were attributed to the C-O-C ether peak of reacted furan and to the stretching of the C-N bond of the maleimide ring, respectively, and confirmed the successful crosslinking between the furan and the bismaleimide moieties. It is worth noting that the intensity of the peaks at $737 \mathrm{~cm}^{-1}$ and $1073 \mathrm{~cm}^{-1}$ attributed out-of-plane bending $\mathrm{C}-\mathrm{H}$ and to the C-O-C ether bonds of furan, respectively, decreased due to the formation of the Diels-Alder adduct [17].

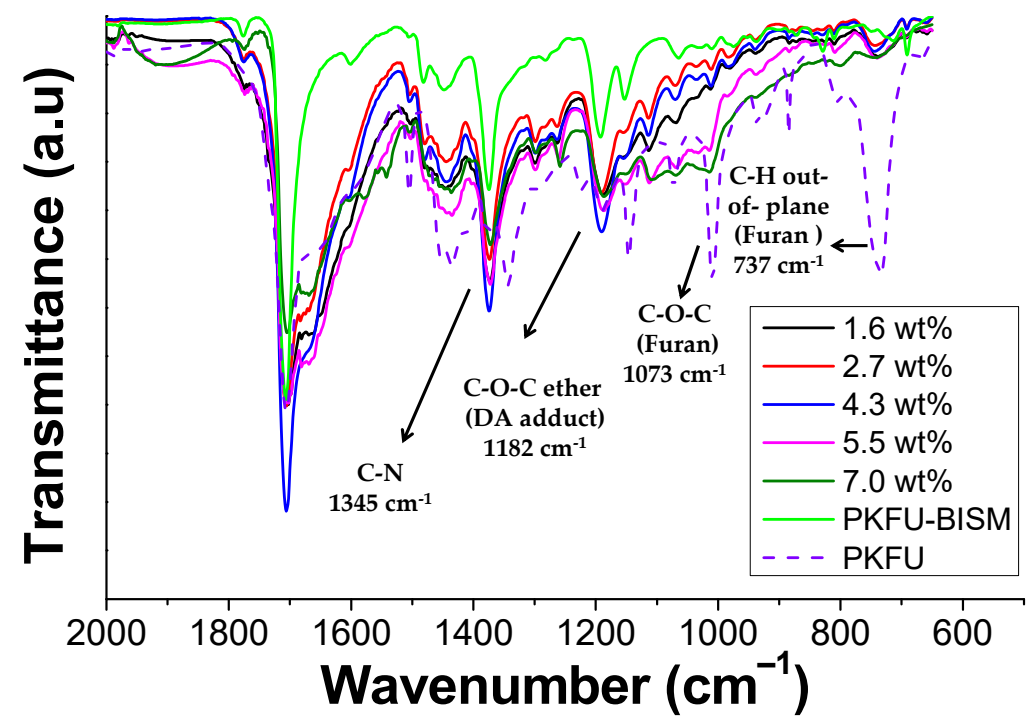

Figure 5. FT-IR spectra of the modified non-cross-linked polymer (PKFU), modified cross-linked polymer (PKFU-BISM), and of the modified cross-linked nanocomposite (PKFU/BISM/rGO).

We characterized all the crosslinked samples by differential scanning calorimetry (DSC) to determine the thermal behavior of the material and the reversibility of the crosslinking process upon three subsequent cycles of heating and cooling. For brevity, we show only the thermogram obtained from the polymer containing $5.5 \mathrm{wt} \%$ of nanofiller, while reporting all other results in the supporting information section (Figures S1 and S2). Figure 6 shows the three heating and cooling cycles, all displaying the occurrence of the retro Diels-Alder reaction (endothermic peaks) and the re-formation of the network during cooling. Both broad endothermic and exothermic processes can be found in the range between $120-180^{\circ} \mathrm{C}$.

In the heating experiments, the peak maximum corresponds to the temperature at which the majority of the Diels-Alder adducts are broken and the area associated to the peak indicates the energy absorbed during the cleavage of the adducts. We calculated the temperature and the energy needed to cleavage the adducts related to the maximum of the peak for each sample (Figure 6 and Figure S1). 


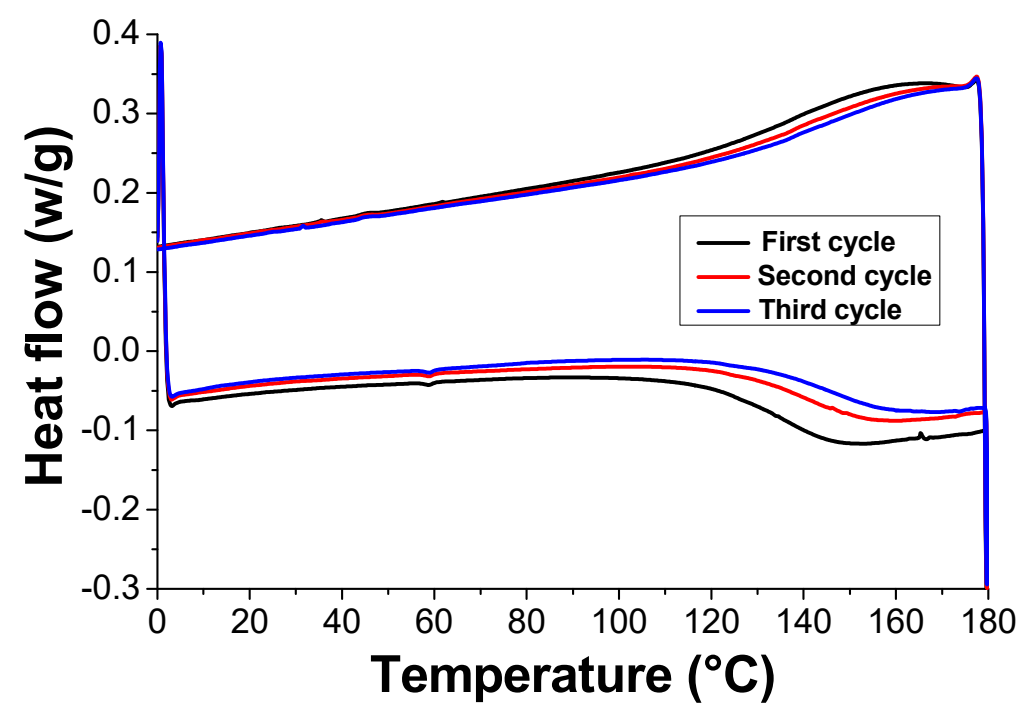

Figure 6. DSC thermogram of the cross-linked nanocomposite containing the $5.5 \mathrm{wt} \%$ of rGO.

Notably, as seen in Figure 7 as the temperature increased by more than $10{ }^{\circ} \mathrm{C}$ with the filler content, the energy substantially diminished by about $1.25 \mathrm{~J} / \mathrm{g}$, thus indicating that rGO affected the thermal stability of the crosslinked system. This effect was already observed in PKFU networks doped with MWCNTs although apparently smaller than that reported here for rGO [15].

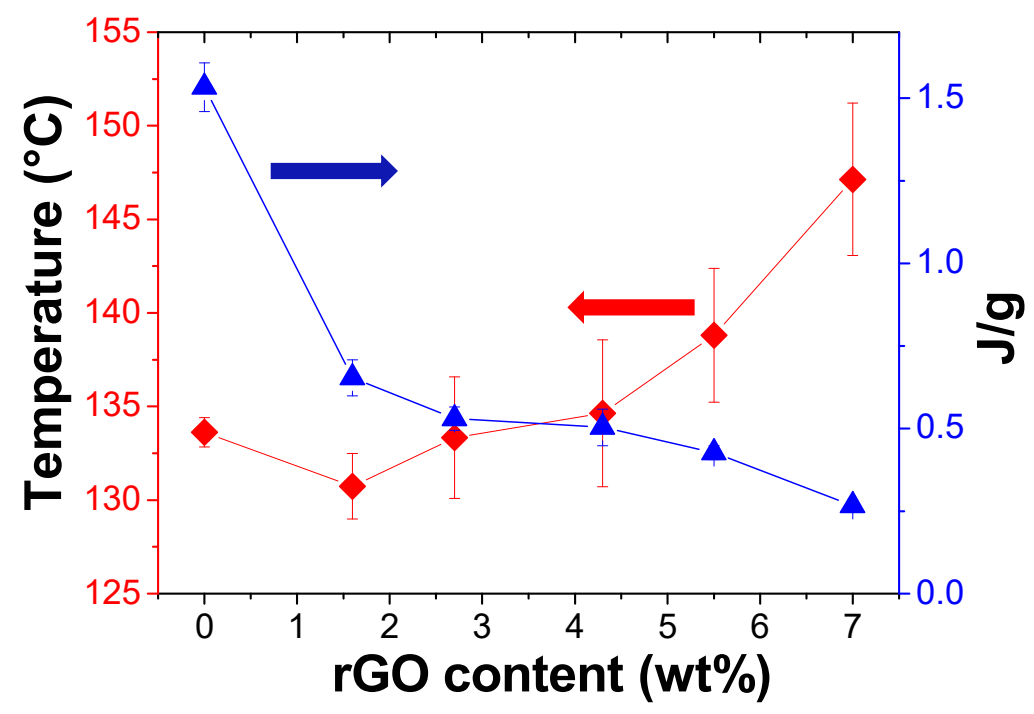

Figure 7. Temperature peak $(\diamond)$ and enthalpy $(\boldsymbol{\Delta})$ where most of the DA adducts are cleaved for all the series of PKFU/BISM/rGO composites at different rGO content.

The mechanical behavior of the composites as a function of temperature was investigated by dynamic mechanical thermal analysis (DMTA) in the range from $40^{\circ} \mathrm{C}$ to $180^{\circ} \mathrm{C}$ (Figure 8). The bar samples for the DMTA analysis were obtained by compression molding of grinded crosslinked composites at $150{ }^{\circ} \mathrm{C}$ and $40 \mathrm{bar}$ for $30 \mathrm{~min}$. This method promotes the rDA mechanism and consequently the de-crosslinking of the thermoset nanocomposite. This behavior evidences the reversible and recyclable nature of these composite materials. The variation in storage modulus $\left(E^{\prime}\right)$, loss modulus $\left(E^{\prime \prime}\right)$ and tan $\delta$ (softening point) were measured as a function of the rGO content. All samples show an initial slow decrease of the storage modulus and a corresponding increase of the loss modulus until a maximum value is reached which corresponds to the softening point of the material. After this point, a faster decrease of both moduli occurs due to the higher softening rate of the material. Notably, 
both loss and elastic moduli and softening point rise substantially for rGO contents higher than $5 \mathrm{wt} \%$, thus confirming the reinforcement characteristics of the graphitic fillers in polymers [15]. Remarkably, the softening point increased from $\sim 120{ }^{\circ} \mathrm{C}$ for the composite with a $1.6-4.3 \mathrm{wt} \%$ of rGO to values higher than $140{ }^{\circ} \mathrm{C}$ at loadings larger than $5.5 \mathrm{wt} \%$. This effect could be possibly attributed to the interfacial interactions between graphitic filler and the polymer. rGO concentrations higher than $7 \mathrm{wt} \%$ seem to show minor reinforcements effects possibly due to less effective phase dispersion of the filler in the polymer matrix at the highest content.
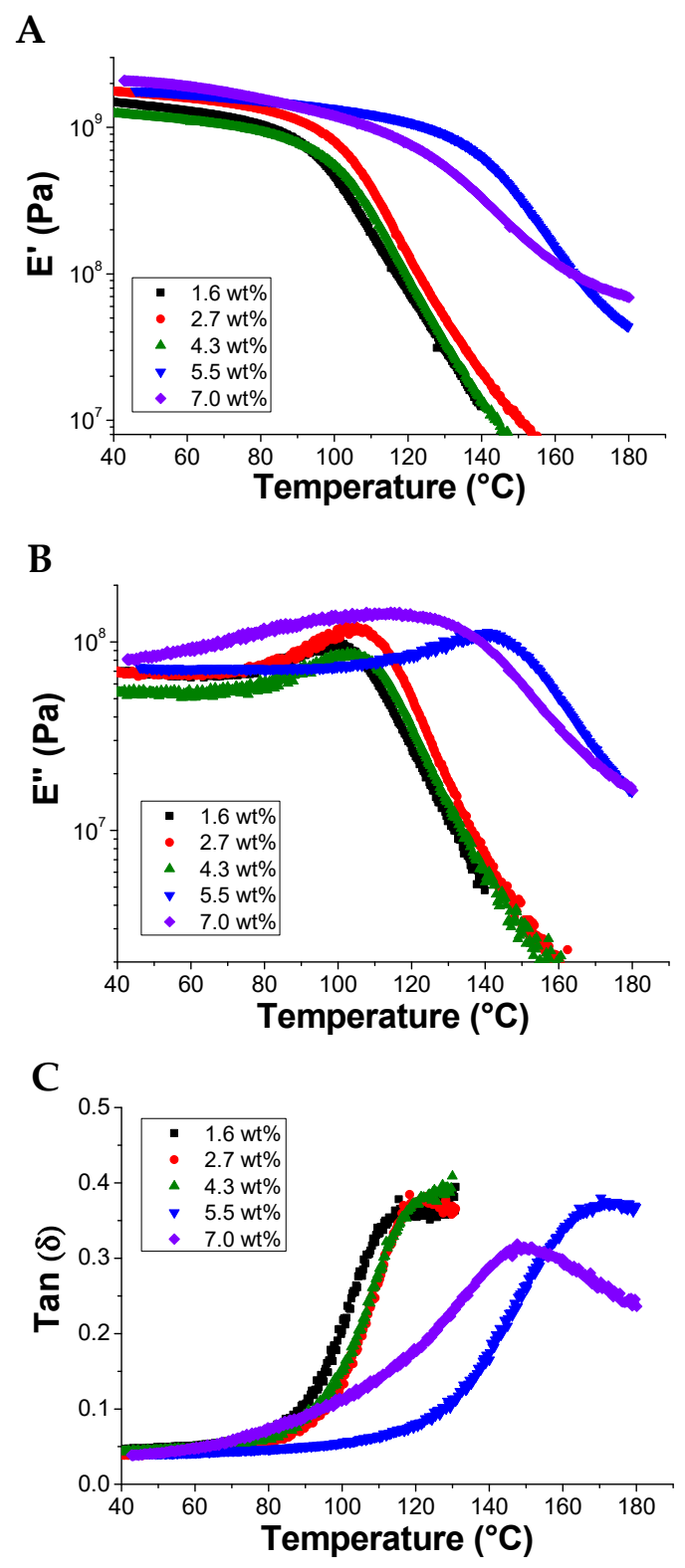

Figure 8. Storage modulus $\mathrm{E}^{\prime}(\mathbf{A})$, loss modulus $\mathrm{E}^{\prime \prime}(\mathbf{B})$ and $\tan \delta(\mathbf{C})$ of the rGO/PKFUBISM with different amounts of $\mathrm{rGO}$ as a function of the temperature.

In order to understand the nature of the interactions between $\mathrm{rGO}$ and the network components, rGO was mixed with PKFU or BISM under the same conditions carried out for the formation of the rGO/PKFUBISM composite. After mixing, the recovered rGO was washed with chloroform several times to remove the non-interacting PKFU or BISM. We then evaluated the amount of PKFU or BISM interacting with rGO by thermogravimetric analysis. The experiments were performed from $25^{\circ} \mathrm{C}$ to $800{ }^{\circ} \mathrm{C}$ under nitrogen atmosphere 
(Figure 9A). PKFU experiences a thermal degradation starting about $350{ }^{\circ} \mathrm{C}$ and showed a weight loss of $70 \%$. rGO begin to degrade at about $200{ }^{\circ} \mathrm{C}$ with a gradual rate and it did not display a plateau even at $800{ }^{\circ} \mathrm{C}$. On the other hand, BISM showed two degradation stages at $250{ }^{\circ} \mathrm{C}$ and around $500{ }^{\circ} \mathrm{C}$ with a total weight loss of $60 \%$. rGO-PKFU also shows two degradation stages one at $200{ }^{\circ} \mathrm{C}$ due to the thermal degradation of the oxygen-functional groups of $\mathrm{rGO}[48]$ and a second one around $350{ }^{\circ} \mathrm{C}$ due to the degradation of PKFU grafted onto rGO. This sample showed an overall weight loss of $5.3 \%$ with respect to the pristine rGO at $800{ }^{\circ} \mathrm{C}$. Conversely, rGO-BISM showed an identical thermal degradation than pristine rGO and an overall weigh loss of only 0.7 with respect to pristine $\mathrm{rGO}$ at $800{ }^{\circ} \mathrm{C}$. Therefore, $\mathrm{PKFU}$ seems to interact better with the surface of rGO with respect to the neat BISM.

The same samples were also characterized in terms of Raman spectroscopy, since it gives useful insights for the structure determination of graphitic materials (Figure 9B). The $D$ band $\left(1340 \mathrm{~cm}^{-1}\right)$ and $G$ band $\left(1580 \mathrm{~cm}^{-1}\right)$ are typical peaks of the rGO Raman spectrum $[50,51]$. The G-band indicates the planar vibration of $\mathrm{sp}^{2}$ carbon atoms forming the graphitic structure whereas the D-band is associated to the scattering from defects that break the fundamental symmetry of the graphene sheet $[52,53]$. The peak centered at $2900 \mathrm{~cm}^{-1}$ is the combination of the first overtone of the D band (2D band) and the D+G band. The ratio of $\mathrm{D}$ and $\mathrm{G}$ bands peak intensities $\left(\mathrm{I}_{\mathrm{D}} / \mathrm{I}_{\mathrm{G}}\right)$ are widely used as standard index to identify defects on $\mathrm{rGO}$ after its functionalization. In this respect, the functionalization of rGO with PKFU inverts the intensities of the $\mathrm{D}$ and $\mathrm{G}-$ band and the $\mathrm{I}_{\mathrm{D}} / \mathrm{I}_{\mathrm{G}}$ ratio of $\mathrm{rGO}$ and rGO-PKFU changed from 1.15 to 0.73 , respectively. This result has already been published for functionalized carbon nanotubes with polyketones bearing furan groups through the Diels-Alder reaction [13]. In addition, rGO-PKFU shows a red-shift and sharpening of the G-Band in comparison to the pristine rGO. Kudin et al., addressed the sharpening and shifting back to graphitic position (shift to lower energies) of the G-Band in rGO after the heating treatment of graphene oxide [54] to the restoration of the rGO aromaticity in the defect regions of the graphene layer [55]. Overall, it seems that the effective interaction between PKFU and rGO could be attributed by a covalent bonding between the two materials and possibly caused by the Diels-Alder between the diene PKFU and the rGO dienophile. Future work will be addressed to investigate the reliability of the proposed mechanism further. Conversely, the functionalization of rGO with BISM slightly modified the intensities of the D and G-band, thus confirming the poor interaction between the crosslinker and the graphitic filler.

A

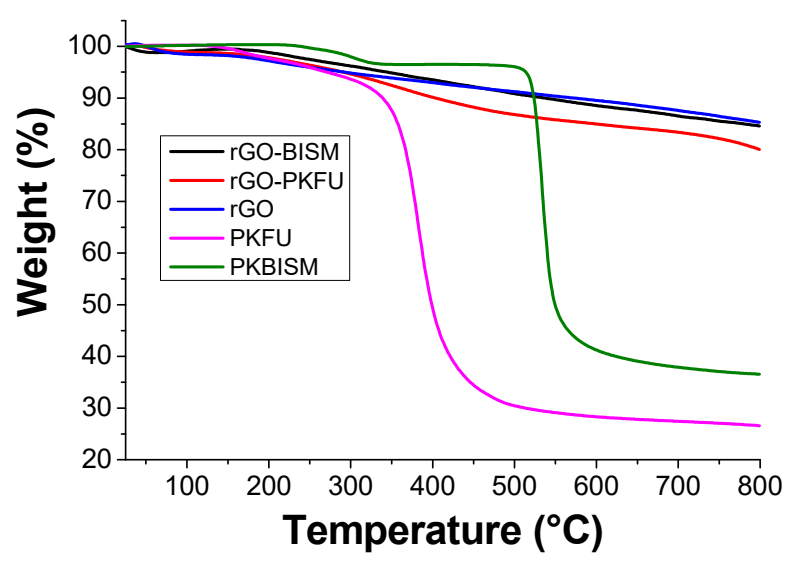

B

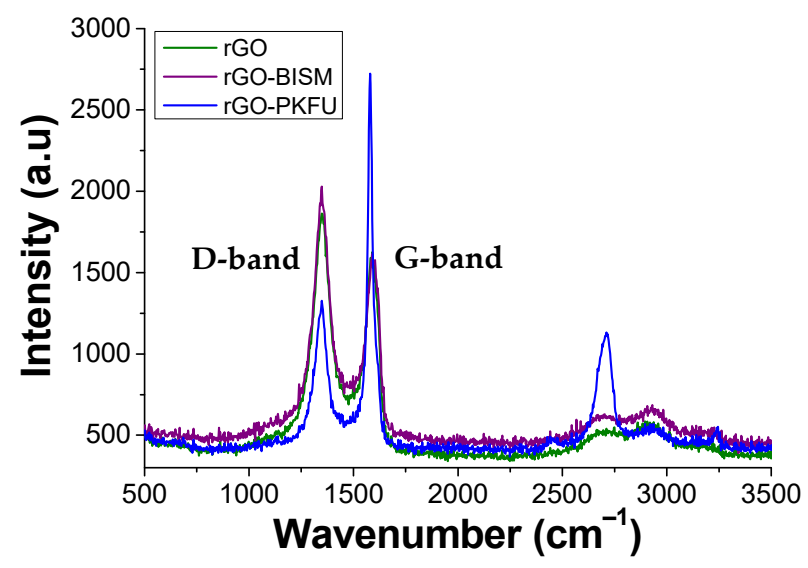

Figure 9. TGA (A) and Raman analysis (B) of rGO mixed with BISM and PKFU.

We also evaluated the morphology of the composite material and the dispersion degree of rGO by SEM microscopy. Figure 10 shows the SEM images of the cross-sectional area of all the investigated nanocomposites and at different magnifications. In general, all samples appear as a smooth polymer matrix that contains assemblies of rGO randomly distributed 
in the form of interacting flakes with the polymer matrix but apparently distributed as isolated clusters. This effect appeared well evident in samples containing the highest amount of rGO (Figure 10D,E for $5.5 \mathrm{wt} \%$ and $7 \mathrm{wt} \%$ of rGO loading). While on one side the interfacial interactions between the polymer matrix and the rGO appeared confirmed, on the other these were not totally effective in providing a homogeneously distributed filler content within the crosslinked PKFU/BISM network.
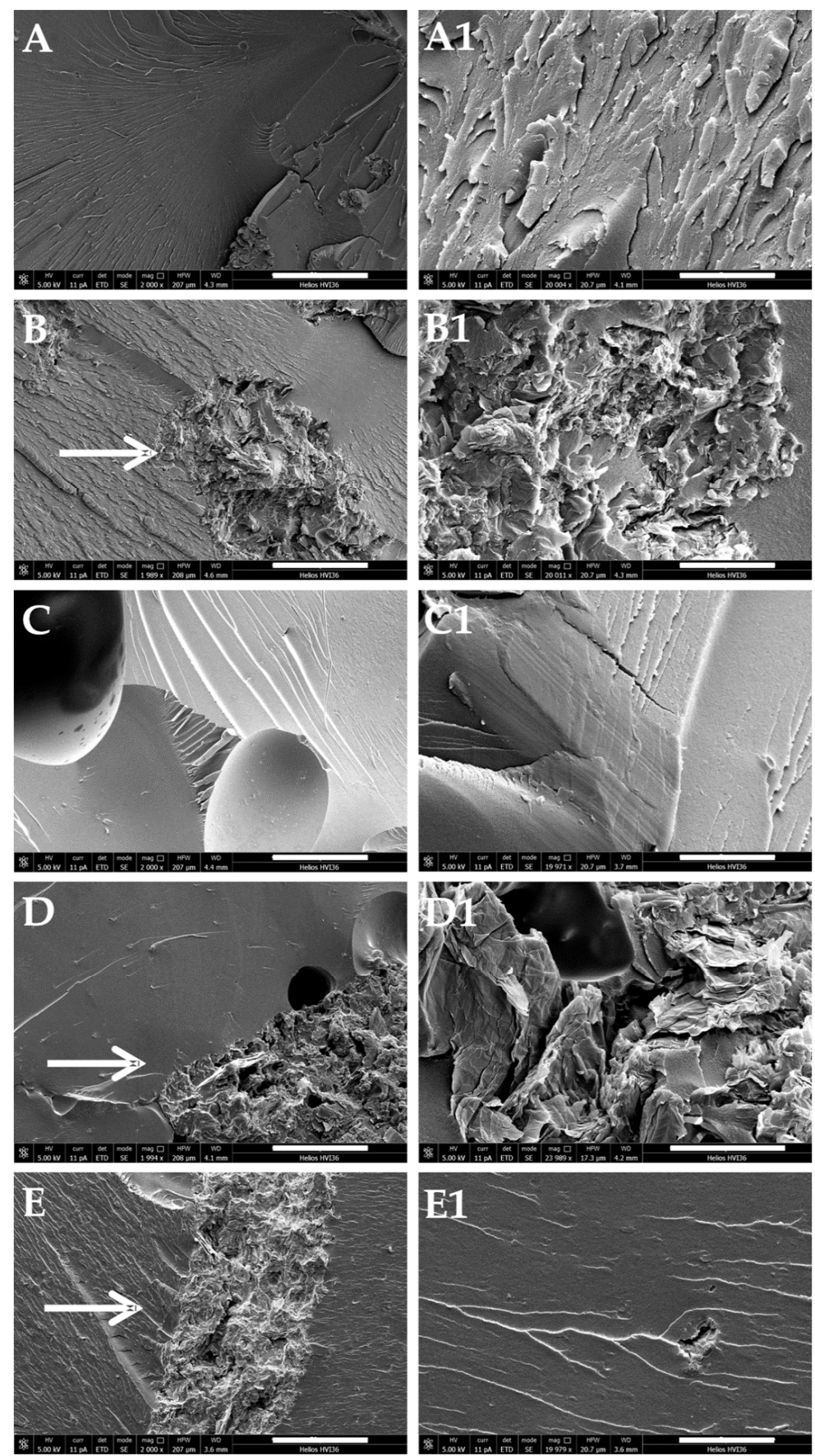

Figure 10. Scanning Electron Microscopy (SEM) micrographs at different magnification of the nanocomposite composed by PKFU/BISM and rGO at different weight percentage. (A,A1) $1.6 \mathrm{wt} \%$, (B,B1) $2.7 \mathrm{wt} \%$, (C,C1) $4.3 \mathrm{wt} \%$, (D,D1) $5.5 \mathrm{wt} \%$, and (E,E1) $7 \mathrm{wt} \%$. Left pictures scale bar $50 \mu \mathrm{m}$, right pictures scale bar $5 \mu \mathrm{m}$. 


\subsection{Electrical Conductivity Properties of PKFU/BISM rGO Nanocomposites}

We then investigated the electric behavior of the nanocomposites in terms of surface resistivity and as a function of the rGO content. Contrary to our expectations, no samples were able to conduct electricity at room temperature (Figure 11) even at the highest rGO content and also after the annealing process carried out at temperature higher than the corresponding softening points. These results could be possibly attributed to the generation of ineffective percolation pathways of conductive rGO assemblies within the polymer network and potentially attributed to the phase dispersion behavior evidenced by the SEM analysis (Figure 10). Conversely, all the investigated nanocomposites started to conduct electricity at temperatures higher than $100^{\circ} \mathrm{C}$ and with absolute surface resistivity values depending on the rGO concentration. The nanocomposite with $\mathrm{rGO}$ content of $1.6 \mathrm{wt} \%$, $2.6 \mathrm{wt} \%, 4.3 \mathrm{wt} \%$ showed surface resistivity around $500 \mathrm{M} \Omega / \mathrm{sq}$ at temperatures higher than $150^{\circ} \mathrm{C}$ (Figure $11 \mathrm{~A}-\mathrm{C}$ ) and after each cycle the temperature fluctuated considerably, suggesting that the nanocomposite is still close to the percolation threshold. Increasing the rGO content, the temperature threshold decreased to $135^{\circ} \mathrm{C}$ and below $100{ }^{\circ} \mathrm{C}$ for the $5.5 \mathrm{wt} \%$ and $7.0 \mathrm{wt} \%$ of filler, respectively. Notably, a substantial decrease in the surface resistivity to below $100 \mathrm{M} \Omega$ /sq occurred at the highest $7 \mathrm{wt} \%$ doping amount of the rGO filler. Such OFF-ON reversible and temperature depending conductive behavior can be due to a combination of effects: (a) during annealing, the polymer becomes softer and the rGO particles are keen to generate effective percolation pathways thanks to their higher mobility within the polymer network; (b) rGO is a typical semiconductor, whose resistance decreases with temperature increase [56-58], thus allowing the polymer network to conduct electricity.

\subsection{Self-Healing and Mechanical Properties of the Nanocomposite}

When testing the recyclability or the self-healing of a new material, mechanical properties are the biggest and most important issue. The recovery of the mechanical properties of the thermoset after the self-healing is essential because otherwise the material cannot be used to any further extent, even if all the other properties are recovered. To test the self-healing effect on the mechanical properties of our material, a bar of the polymer was prepared by compression molding, and DMTA analysis was performed. Then, the bar was broken as reported in Figure 12 and remolded using the same condition used before. Once healed, a second DMTA was collected on the cured sample (Figure 12d). In Figure 12 the pristine bar is shown (a) as well as the broken one $(b, c)$. We noticed that after remolding (d) the bar recovered its original shape without any cracks, thus confirming the self-healing characteristic of the material for this first attempt.

The previous result was confirmed by the DMTA characterization. Storage and loss moduli of the thermoset before and after the self-healing show the same values until $100^{\circ} \mathrm{C}$, while exhibiting an opposite behavior at higher temperature (Figure 13). This behavior was reflected on the softening point of the material, the Tan $(\delta)$, which increased from $\sim 120^{\circ} \mathrm{C}$ to $\sim 140{ }^{\circ} \mathrm{C}$ in the healed sample. The enhanced rigidity of the composite material after healing might be addressed to the presence of $\mathrm{rGO}$, whose interfacial interactions with the PKFU macromolecules become more effective as also recently observed in similar samples containing MWCNTs [15,42,44,47,59]. 
A

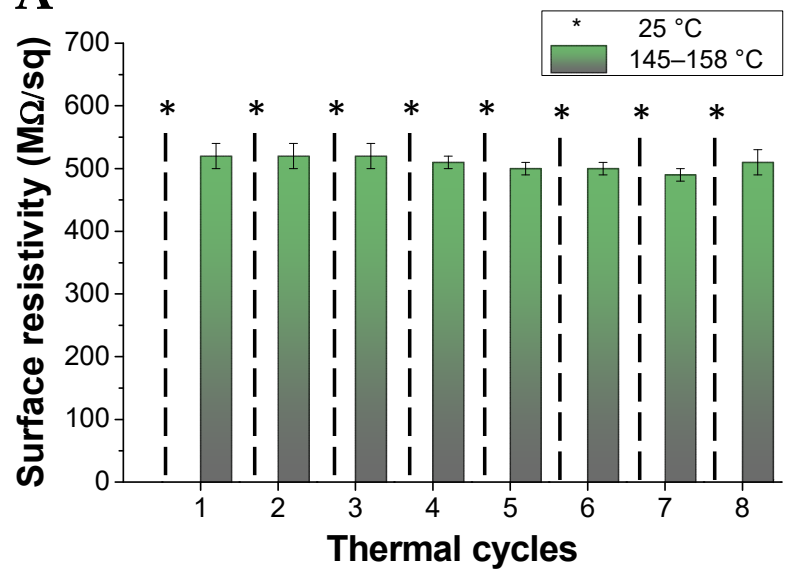

C

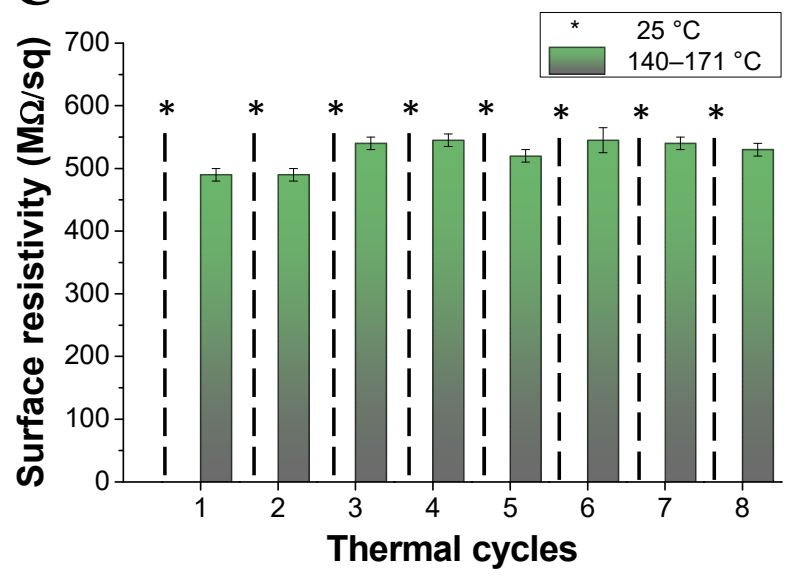

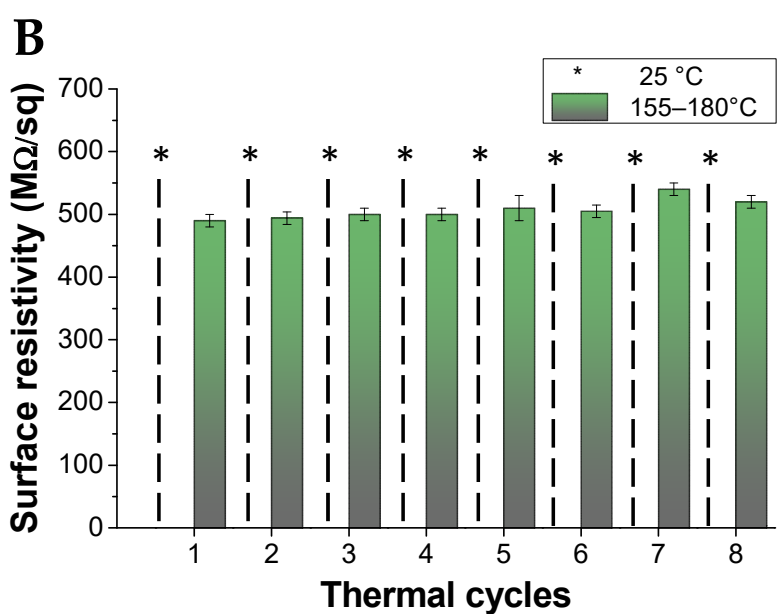

D

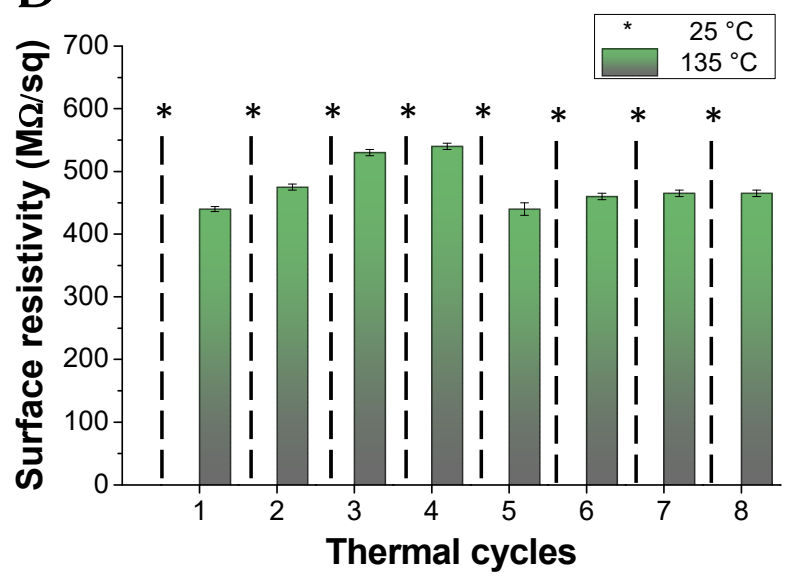

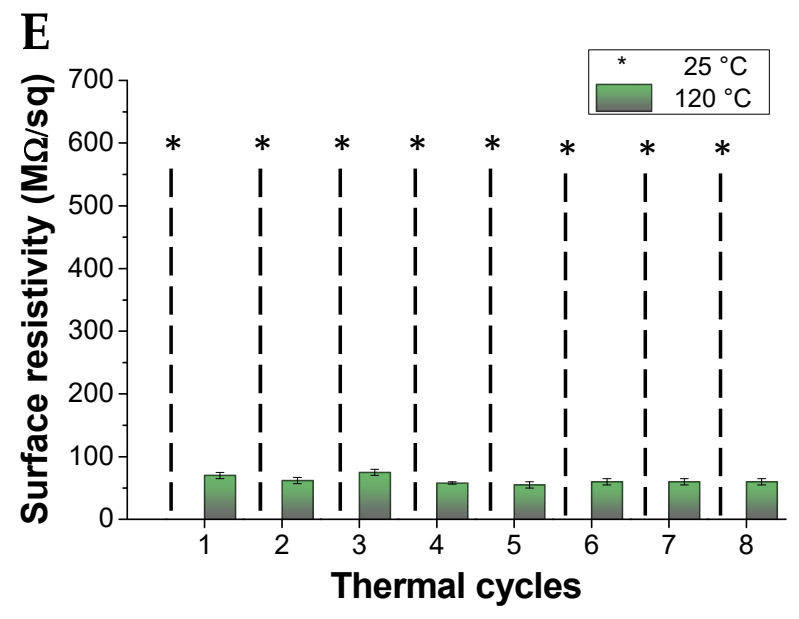

Figure 11. Surface resistivity of the nanocomposite composed by PKFU/BISM and rGO at different weight percentage. (A) $1.6 \mathrm{wt} \%$, (B) $2.7 \mathrm{wt} \%$, (C) $4.3 \mathrm{wt} \%$, (D) $5.5 \mathrm{wt} \%$, and (E) $7 \mathrm{wt} \%$. * $\geq 500 \mathrm{M} \Omega /$ sq. Sample thickness of $1.05 \mathrm{~mm}$. 


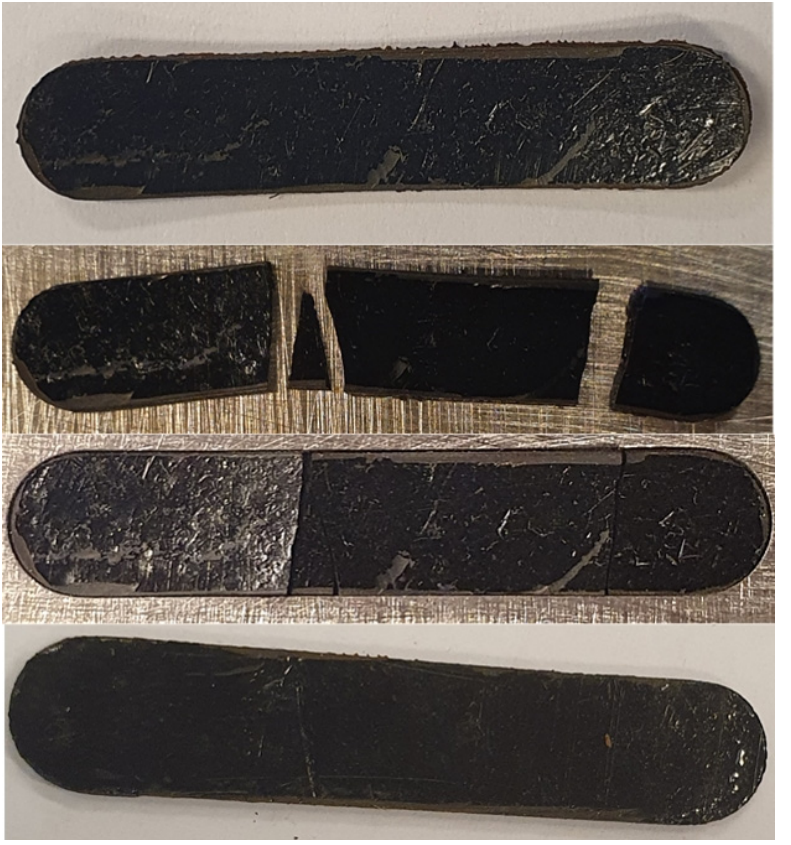

Figure 12. Bar of PKFUBISM containing the $2.7 \mathrm{wt} \%$ of $\mathrm{rGO}$ after molding (a), breaking (b), inside the mold (c) and after self-healing (d). Bar size: $45 \mathrm{~mm}$ long, $5 \mathrm{~mm}$ wide and $1 \mathrm{~mm}$ thick.

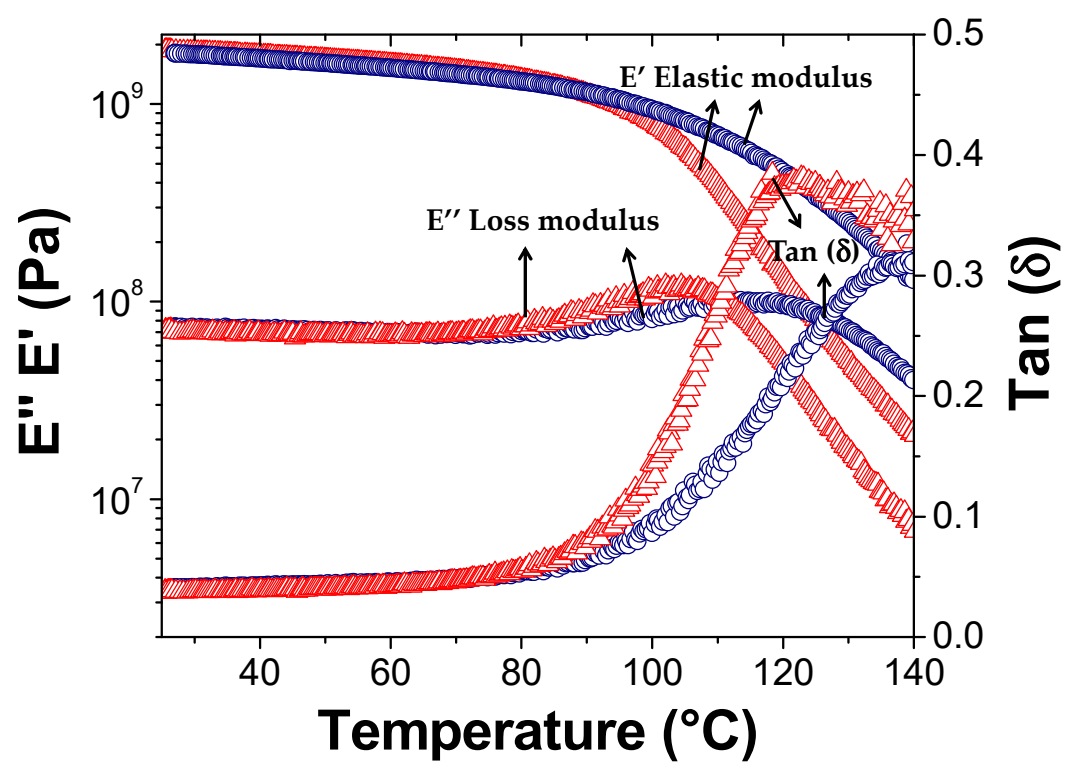

Figure 13. DMTA result of storage modulus $\left(E^{\prime}\right)$, loss modulus $\left(E^{\prime \prime}\right)$ and $\tan (\delta)$ of PKFUBISM/rGO $2.7 \%$ after molding $(\triangle)$ and after the self-healing $(\bigcirc)$.

\section{Conclusions}

In this work, we have prepared a new polymer composite characterized by electrical conductivity and self-healing characteristics triggered by temperature variations. The starting material used for this purpose is a polyketone, obtained by the polymerization of $\mathrm{CO}$, ethylene and propylene. The polyketone was chemically modified by Paal-Knorr reaction using furfurylamine to introduce a furan pendant group onto the backbone of the polymer. The modification of the polyketone with furfurylamine successfully proceeded with a very high yield of about $85 \%$, as confirmed by elemental analysis, FT-IR and ${ }^{1} \mathrm{H}-\mathrm{NMR}$. Nanocomposites were then prepared by solution mixing using reduced graphene oxide as a nanofiller and BISM as crosslinker to confer self-healing properties. After cross-linking via the formation of a Diels-Alder adduct between the furan moieties linked to PK and the 
BISM a cross-linked network was obtained, characterized by a reversible character being destroyed at $120^{\circ} \mathrm{C}$ and reformed at $50^{\circ} \mathrm{C}$ as confirmed by ATR-FTIR and DSC. The increased softening temperature of the cross-linked polymer was confirmed by DMTA which showed a maximum in the tan $\delta$ values of $\sim 120^{\circ} \mathrm{C}$ for the polymer containing $1.6,2.7,4.3 \mathrm{wt} \%$ of nanofiller and $170{ }^{\circ} \mathrm{C}$ for the polymer containing $5.5 \mathrm{wt} \%$. All the nanocomposites showed a storage modulus higher than $10^{6} \mathrm{~Pa}$ for all the investigated temperature, confirming the robustness of the polymer also at high temperature. The electrically conductive behavior of the crosslinked nanocomposite occurred only at temperatures higher than $100{ }^{\circ} \mathrm{C}$ with an OFF-ON behavior possibly addressed to the semiconducting features of rGO distributed in the polymer network in the form apparently isolated clusters as evidenced by SEM microscopy. The self-healing ability of the nanocomposite was confirmed by testing the recovery of the mechanical properties after the breaking and reprocessing processes of the polymer network. Overall, the conductive self-healing nanocomposite reported in this work can be useful for several applications where conductivity is required only at temperature higher than a certain threshold thus suggesting the development of electronic switches triggered by temperature. Notably, this smart material is also cost-effective thanks to the favorable selection of low-cost materials and the small amount of required rGO.

Supplementary Materials: The following are available online at https:/ /www.mdpi.com/2073-4 360/13/3/339/s1. Figure S1. DSC thermal cycles of PKFU/BM/rGO nanocomposites at different rGO content $(w \mathrm{t} \%)$. Figure S2. TGA of the PKFU/BM/rGO nanocomposites at different rGO content $(w t \%)$.

Author Contributions: Conceptualization, A.P.; methodology, E.A.-H., A.G., F.P., G.M.R.L. and V.M.; investigation E.A.-H., F.P., F.O., G.M.R.L. and A.G.; data curation, E.A.-H., A.P.; writing-original draft preparation, E.A.-H. and R.K.B.; writing-review and editing, A.P.; funding acquisition, V.M., F.P. All authors have read and agreed to the published version of the manuscript.

Funding: This research received no external funding.

Institutional Review Board Statement: Not applicable.

Informed Consent Statement: Not applicable.

Data Availability Statement: The data presented in this study are available on request from the corresponding author.

Acknowledgments: CISUP-Centre for Instrumentation Sharing-University of Pisa is kindly acknowledged for STEM measurements.

Conflicts of Interest: The authors declare no conflict of interest.

\section{References}

1. Gillies, E.R. Reflections on the Evolution of Smart Polymers. Isr. J. Chem. 2020, 60, 75-85. [CrossRef]

2. Mukherji, D.; Marques, C.M.; Kremer, K. Smart Responsive Polymers: Fundamentals and Design Principles. Annu. Rev. Condens. Matter Phys. 2020, 11, 271-299. [CrossRef]

3. Hoffman, A.S.; Stayton, P.S. 1.3.2G-Applications of "Smart Polymers" as Biomaterials. In Biomaterials Science, 4th ed.; Wagner, W.R., Sakiyama-Elbert, S.E., Zhang, G., Yaszemski, M.J., Eds.; Academic Press: Cambridge, MA, USA, 2020; pp. 191-203. [CrossRef]

4. Convertine, A.J.; Lokitz, B.S.; Vasileva, Y.; Myrick, L.J.; Scales, C.W.; Lowe, A.B.; McCormick, C.L. Direct Synthesis of Thermally Responsive DMA/NIPAM Diblock and DMA/NIPAM/DMA Triblock Copolymers via Aqueous, Room Temperature RAFT Polymerization. Macromolecules 2006, 39, 1724-1730. [CrossRef]

5. Mahmoodzadeh, F.; Hosseinzadeh, M.; Jannat, B.; Ghorbani, M. Fabrication and characterization of gold nanospheres-cored pH-sensitive thiol-ended triblock copolymer: A smart drug delivery system for cancer therapy. Polym. Adv. Technol. 2019, 30, 1344-1355. [CrossRef]

6. Hajebi, S.; Abdollahi, A.; Roghani-Mamaqani, H.; Salami-Kalajahi, M. Hybrid and hollow Poly(N,N-dimethylaminoethyl methacrylate) nanogels as stimuli-responsive carriers for controlled release of doxorubicin. Polymer 2019, 180, 121716. [CrossRef]

7. Reglero Ruiz, A.J.; Sanjuán, M.A.; Vallejos, S.; García, C.F.; García, M.J. Smart Polymers in Micro and Nano Sensory Devices. Chemosensors 2018, 6, 12. [CrossRef]

8. You, Q.; Zhang, Y.; Zhang, Q.; Guo, J.; Huang, W.; Shi, S.; Chen, X. High-capacity thermo-responsive magnetic molecularly imprinted polymers for selective extraction of curcuminoids. J. Chromatogr. A 2014, 1354, 1-8. [CrossRef] 
9. Ngang, H.P.; Ahmad, A.L.; Low, S.C.; Ooi, B.S. Preparation of thermoresponsive PVDF $/ \mathrm{SiO}_{2}$-PNIPAM mixed matrix membrane for saline oil emulsion separation and its cleaning efficiency. Desalination 2017, 408, 1-12. [CrossRef]

10. Idumah, C.I.; Nwuzor, I.; Odera, S.R. Recent advancements in self-healing polymeric hydrogels, shape memory, and stretchable materials. Int. J. Polym. Mater. Polym. Biomater. 2020, 1-26. [CrossRef]

11. Jong Se, P.; Takahashi, K.; Guo, Z.; Wang, Y.; Bolanos, E.; Hamann-Schaffner, C.; Murphy, E.; Wudl, F.; Hahn, H.T. Towards Development of a Self-Healing Composite using a Mendable Polymer and Resistive Heating. J. Compos. Mater. 2008, 42, $2869-2881$. [CrossRef]

12. Fuhrmann, A.; Göstl, R.; Wendt, R.; Kötteritzsch, J.; Hager, M.D.; Schubert, U.S.; Brademann-Jock, K.; Thünemann, A.F.; Nöchel, U.; Behl, M.; et al. Conditional repair by locally switching the thermal healing capability of dynamic covalent polymers with light. Nat. Commun. 2016, 7, 13623. [CrossRef]

13. Araya-Hermosilla, R.; Pucci, A.; Raffa, P.; Santosa, D.; Pescarmona, P.P.; Gengler, Y.N.R.; Rudolf, P.; Moreno-Villoslada, I.; Picchioni, F. Electrically-Responsive Reversible Polyketone/MWCNT Network through Diels-Alder Chemistry. Polymers 2018, 10, 1076. [CrossRef]

14. Araya-Hermosilla, R.; Broekhuis, A.A.; Picchioni, F. Reversible polymer networks containing covalent and hydrogen bonding interactions. Eur. Polym. J. 2014, 50, 127-134. [CrossRef]

15. Macedo, R.; Lima, G.; Orozco, F.; Picchioni, F.; Moreno-Villoslada, I.; Pucci, A.; Bose, K.R.; Araya-Hermosilla, R. Electrically Self-Healing Thermoset MWCNTs Composites Based on Diels-Alder and Hydrogen Bonds. Polymers 2019, 11, 1885. [CrossRef]

16. Toncelli, C.; De Reus, D.C.; Picchioni, F.; Broekhuis, A.A. Properties of Reversible Diels-Alder Furan/Maleimide Polymer Networks as Function of Crosslink Density. Macromol. Chem. Phys. 2012, 213, 157-165. [CrossRef]

17. Zhang, Y.; Broekhuis, A.A.; Picchioni, F. Thermally Self-Healing Polymeric Materials: The Next Step to Recycling Thermoset Polymers? Macromolecules 2009, 42, 1906-1912. [CrossRef]

18. Araya-Hermosilla, R.; Lima, G.M.R.; Raffa, P.; Fortunato, G.; Pucci, A.; Flores, M.E.; Moreno-Villoslada, I.; Broekhuis, A.A.; Picchioni, F. Intrinsic self-healing thermoset through covalent and hydrogen bonding interactions. Eur. Polym. J. 2016, 81, 186-197. [CrossRef]

19. Zhang, Y.; Broekhuis, A.A.; Stuart, M.C.A.; Picchioni, F. Polymeric amines by chemical modifications of alternating aliphatic polyketones. J. Appl. Polym. Sci. 2008, 107, 262-271. [CrossRef]

20. Araya-Hermosilla, E.A.; Carlotti, M.; Picchioni, F.; Mattoli, V.; Pucci, A. Electrically-Conductive Polyketone Nanocomposites Based on Reduced Graphene Oxide. Polymers 2020, 12, 923. [CrossRef]

21. Figaroa Patrick, A.; Miedema, H.; Euverink, G.-J.; Picchioni, F. Functional polyketones for the removal of calcium and magnesium from water (part I): Synthesis and chemical characterization. In Pure and Applied Chemistry; De Gruyter: Berlin, Germany, 2017; Volume 89, p. 41.

22. Araya-Hermosilla, E.; Orellana, S.L.; Toncelli, C.; Picchioni, F.; Moreno-Villoslada, I. Novel polyketones with pendant imidazolium groups as nanodispersants of hydrophobic antibiotics. J. Appl. Polym. Sci. 2015, 132. [CrossRef]

23. Hayes, S.A.; Jones, F.R.; Marshiya, K.; Zhang, W. A self-healing thermosetting composite material. Compos. Part A Appl. Sci. Manuf. 2007, 38, 1116-1120. [CrossRef]

24. Liu, Y.-L.; Chuo, T.-W. Self-healing polymers based on thermally reversible Diels-Alder chemistry. Polym. Chem. 2013, 4, 2194-2205. [CrossRef]

25. Orozco, F.; Li, J.; Ezekiel, U.; Niyazov, Z.; Floyd, L.; Lima, G.M.R.; Winkelman, J.G.M.; Moreno-Villoslada, I.; Picchioni, F.; Bose, R.K. Diels-Alder-based thermo-reversibly crosslinked polymers: Interplay of crosslinking density, network mobility, kinetics and stereoisomerism. Eur. Polym. J. 2020, 135, 109882. [CrossRef]

26. Rafiee, M.A.; Rafiee, J.; Yu, Z.Z.; Koratkar, N. Buckling resistant graphene nanocomposites. Appl. Phys. Lett. 2009, 95, 223103. [CrossRef]

27. Rafiee, M.A.; Rafiee, J.; Wang, Z.; Song, H.; Yu, Z.-Z.; Koratkar, N. Enhanced Mechanical Properties of Nanocomposites at Low Graphene Content. ACS Nano 2009, 3, 3884-3890. [CrossRef]

28. Xie, S.H.; Liu, Y.Y.; Li, J.Y. Comparison of the effective conductivity between composites reinforced by graphene nanosheets and carbon nanotubes. Appl. Phys. Lett. 2008, 92, 243121. [CrossRef]

29. Kuilla, T.; Bhadra, S.; Yao, D.; Kim, N.H.; Bose, S.; Lee, J.H. Recent advances in graphene based polymer composites. Prog. Polym. Sci. 2010, 35, 1350-1375. [CrossRef]

30. Pokharel, P.; Choi, S.; Lee, D.S. The effect of hard segment length on the thermal and mechanical properties of polyurethane/graphene oxide nanocomposites. Compos. Part A Appl. Sci. Manuf. 2015, 69, 168-177. [CrossRef]

31. Lin, L.; Peng, H.; Liu, Z. Synthesis challenges for graphene industry. Nat. Mater. 2019, 18, 520-524. [CrossRef]

32. Fan, H.; Wang, L.; Zhao, K.; Li, N.; Shi, Z.; Ge, Z.; Jin, Z. Fabrication, Mechanical Properties, and Biocompatibility of GrapheneReinforced Chitosan Composites. Biomacromolecules 2010, 11, 2345-2351. [CrossRef]

33. Xu, Y.; Bai, H.; Lu, G.; Li, C.; Shi, G. Flexible Graphene Films via the Filtration of Water-Soluble Noncovalent Functionalized Graphene Sheets. J. Am. Chem. Soc. 2008, 130, 5856-5857. [CrossRef]

34. Gilje, S.; Han, S.; Wang, M.; Wang, K.L.; Kaner, R.B. A Chemical Route to Graphene for Device Applications. Nano Lett. 2007, 7, 3394-3398. [CrossRef]

35. Dikin, D.A.; Stankovich, S.; Zimney, E.J.; Piner, R.D.; Dommett, G.H.B.; Evmenenko, G.; Nguyen, S.T.; Ruoff, R.S. Preparation and characterization of graphene oxide paper. Nature 2007, 448, 457-460. [CrossRef] 
36. Gupta, B.; Kumar, N.; Panda, K.; Kanan, V.; Joshi, S.; Visoly-Fisher, I. Role of oxygen functional groups in reduced graphene oxide for lubrication. Sci. Rep. 2017, 7, 45030. [CrossRef]

37. Menes, O.; Cano, M.; Benedito, A.; Giménez, E.; Castell, P.; Maser, W.K.; Benito, A.M. The effect of ultra-thin graphite on the morphology and physical properties of thermoplastic polyurethane elastomer composites. Compos. Sci. Technol. 2012, 72, 1595-1601. [CrossRef]

38. Feng, H.; Li, Y.; Li, J. Strong reduced graphene oxide-Polymer composites: Hydrogels and wires. RSC Adv. 2012, 2, 6988-6993. [CrossRef]

39. Layek, R.K.; Samanta, S.; Nandi, A.K. The physical properties of sulfonated graphene/poly(vinyl alcohol) composites. Carbon 2012, 50, 815-827. [CrossRef]

40. Huang, X.; Qi, X.; Boey, F.; Zhang, H. Graphene-based composites. Chem. Soc. Rev. 2012, 41, 666-686. [CrossRef]

41. Luceño-Sánchez, A.J.; Díez-Pascual, M.A. Grafting of Polypyrrole-3-carboxylic Acid to the Surface of Hexamethylene DiisocyanateFunctionalized Graphene Oxide. Nanomaterials 2019, 9, 1095. [CrossRef]

42. Cano, M.; Khan, U.; Sainsbury, T.; O’Neill, A.; Wang, Z.; McGovern, I.T.; Maser, W.K.; Benito, A.M.; Coleman, J.N. Improving the mechanical properties of graphene oxide based materials by covalent attachment of polymer chains. Carbon 2013, 52, 363-371. [CrossRef]

43. Castell, P.; Cano, M.; Maser, W.K.; Benito, A.M. Combination of two dispersants as a valuable strategy to prepare improved poly(vinyl alcohol)/carbon nanotube composites. Compos. Sci. Technol. 2013, 80, 101-107. [CrossRef]

44. Liang, J.; Huang, Y.; Zhang, L.; Wang, Y.; Ma, Y.; Guo, T.; Chen, Y. Molecular-Level Dispersion of Graphene into Poly(vinyl alcohol) and Effective Reinforcement of their Nanocomposites. Adv. Funct. Mater. 2009, 19, 2297-2302. [CrossRef]

45. Wang, Z.; Guo, Y.; Yan, L.; Bian, J.; Liu, H.; Huang, H.; Lin, H.; Sude, M.; Lijun, W.; Gu, Z. Mechanical properties and morphologies of polypropylene composites synergistically reinforced-toughened by styrene-butadiene rubber and graphene oxide nanosheets. J. Thermoplast. Compos. Mater. 2019, 33, 413-431. [CrossRef]

46. Gudkov, M.V.; Ryvkina, N.G.; Gorenberg, A.Y.; Melnikov, V.P. Electrically conductive nanocomposites with segregated structure based on poly(vinylidene fluoride-co-tetrafluoroethylene) and reduced graphene oxide. Dokl. Phys. Chem. 2016, 466, 1-3. [CrossRef]

47. Cheng, H.K.F.; Sahoo, N.G.; Tan, Y.P.; Pan, Y.; Bao, H.; Li, L.; Chan, S.H.; Zhao, J. Poly(vinyl alcohol) Nanocomposites Filled with Poly(vinyl alcohol)-Grafted Graphene Oxide. ACS Appl. Mater. Interfaces 2012, 4, 2387-2394. [CrossRef]

48. Araya-Hermosilla, E.; Minichino, M.; Mattoli, V.; Pucci, A. Chemical and Temperature Sensors Based on Functionalized Reduced Graphene Oxide. Chemosensors 2020, 8, 43. [CrossRef]

49. Mul, W.P.; Dirkzwager, H.; Broekhuis, A.A.; Heeres, H.J.; van der Linden, A.J.; Guy Orpen, A. Highly active, recyclable catalyst for the manufacture of viscous, low molecular weight, CO-ethene-propene-based polyketone, base component for a new class of resins. Inorg. Chim. Acta 2002, 327, 147-159. [CrossRef]

50. Wu, J.-B.; Lin, M.-L.; Cong, X.; Liu, H.-N.; Tan, P.-H. Raman spectroscopy of graphene-based materials and its applications in related devices. Chem. Soc. Rev. 2018, 47, 1822-1873. [CrossRef]

51. Vryonis, O.; Andritsch, T.; Vaughan, A.S.; Lewin, P.L. An alternative synthesis route to graphene oxide: Influence of surface chemistry on charge transport in epoxy-based composites. J. Mater. Sci. 2019, 54, 8302-8318. [CrossRef]

52. Cançado, L.G.; Jorio, A.; Ferreira, E.H.M.; Stavale, F.; Achete, C.A.; Capaz, R.B.; Moutinho, M.V.O.; Lombardo, A.; Kulmala, T.S.; Ferrari, A.C. Quantifying Defects in Graphene via Raman Spectroscopy at Different Excitation Energies. Nano Lett. 2011, 11, 3190-3196. [CrossRef]

53. Muhammad Hafiz, S.; Ritikos, R.; Whitcher, T.J.; Md Razib, N.; Bien, D.C.S.; Chanlek, N.; Nakajima, H.; Saisopa, T.; Songsiriritthigul, P.; Huang, N.M.; et al. A practical carbon dioxide gas sensor using room-temperature hydrogen plasma reduced graphene oxide. Sens. Actuators B Chem. 2014, 193, 692-700. [CrossRef]

54. Kudin, K.N.; Ozbas, B.; Schniepp, H.C.; Prud'homme, R.K.; Aksay, I.A.; Car, R. Raman Spectra of Graphite Oxide and Functionalized Graphene Sheets. Nano Lett. 2008, 8, 36-41. [CrossRef] [PubMed]

55. Setaro, A.; Adeli, M.; Glaeske, M.; Przyrembel, D.; Bisswanger, T.; Gordeev, G.; Maschietto, F.; Faghani, A.; Paulus, B.; Weinelt, M.; et al. Preserving $\pi$-conjugation in covalently functionalized carbon nanotubes for optoelectronic applications. Nat. Commun. 2017, 8, 14281. [CrossRef] [PubMed]

56. Muchharla, B.; Narayanan, T.N.; Balakrishnan, K.; Ajayan, P.M.; Talapatra, S. Temperature dependent electrical transport of disordered reduced graphene oxide. 2D Mater. 2014, 1, 011008. [CrossRef]

57. Gómez-Navarro, C.; Weitz, R.T.; Bittner, A.M.; Scolari, M.; Mews, A.; Burghard, M.; Kern, K. Electronic Transport Properties of Individual Chemically Reduced Graphene Oxide Sheets. Nano Lett. 2007, 7, 3499-3503. [CrossRef]

58. Eda, G.; Mattevi, C.; Yamaguchi, H.; Kim, H.; Chhowalla, M. Insulator to Semimetal Transition in Graphene Oxide. J. Phys. Chem. C 2009, 113, 15768-15771. [CrossRef]

59. Zhang, S.; Liu, P.; Zhao, X.; Xu, J. Preparation of poly(vinyl alcohol)-grafted graphene oxide/poly(vinyl alcohol) nanocomposites via in-situ low-temperature emulsion polymerization and their thermal and mechanical characterization. Appl. Surf. Sci. 2017, 396, 1098-1107. [CrossRef] 